\title{
Recovering from co-dependence: a study of Iranian wives of persons with substance use disorder
}

\begin{abstract}
Spouses of persons with substance use disorder are likely to suffer from co-dependence, requiring their own process of recovery. Limited research exists, however, describing the process of recovery from co-dependence for this group in Iran. This study aimed to describe recovery from co-dependence among wives of persons with substance use disorder in NarAnon self-help groups in Iran. A qualitative case study design was employed to conduct the study. Eleven Iranian wives were selected by purposive snowball sampling technique. Data were collected through face-to-face interviews, non-participation observations and documents. Analyzing the findings through constant comparative method revealed seven interconnected stages of recovery from co-dependence: support system of Nar-Anon, raising awareness, accepting reality, growing spiritually, detaching from unhealthy dependency, being responsible for oneself, and transferring the message of Nar-Anon to others. The findings of this study shed light on the importance of support systems and spirituality in the process of recovery from co-dependence. Dealing with enabling behaviors in the process of recovery was also discussed.
\end{abstract}

Keyword: Recovery from co-dependence; Wives of persons with substance use disorder; Nar-anon self-help group; 12-step program; Spirituality; Enabling behaviors 